\title{
Polymodal Functionality of C. elegans OLL Neurons in Mechanosensation and Thermosensation
}

\author{
Yuedan Fan ${ }^{1,2} \cdot$ Wenjuan Zou ${ }^{1,2} \cdot$ Jia Liu $^{1,2} \cdot$ Umar Al-Sheikh $^{1,2}$ (10) \\ Hankui Cheng ${ }^{1,2} \cdot$ Duo Duan ${ }^{1,2} \cdot$ Du Chen ${ }^{1,2} \cdot$ Siyan Liu ${ }^{1,2} \cdot$ Luyi Chen $^{3}$. \\ Jilei $\mathrm{Xu}^{3} \cdot$ Firdosh Ruhomutally $^{4} \cdot$ Lijun Kang $^{1,2}{ }^{(1)}$
}

Received: 3 May 2020/ Accepted: 25 August 2020/Published online: 8 February 2021

(C) The Author(s) 2021

\begin{abstract}
Sensory modalities are important for survival but the molecular mechanisms remain challenging due to the polymodal functionality of sensory neurons. Here, we report the C. elegans outer labial lateral (OLL) sensilla sensory neurons respond to touch and cold. Mechanosensation of OLL neurons resulted in cell-autonomous mechanically-evoked $\mathrm{Ca}^{2+}$ transients and rapidly-adapting mechanoreceptor currents with a very short latency. Mechanotransduction of OLL neurons might be carried by a novel $\mathrm{Na}^{+}$conductance channel, which is insensitive to amiloride. The bona fide mechano-gated $\mathrm{Na}^{+}$-selective degenerin/epithelial $\mathrm{Na}^{+}$channels, TRP-4, TMC, and Piezo proteins are not involved in this mechanosensation. Interestingly, OLL neurons also mediated cold but not warm responses in a cell-autonomous manner. We further showed that the cold response of OLL neurons is not mediated by the cold receptor TRPA-1 or the temperature-
\end{abstract}

Yuedan Fan, Wenjuan Zou, Jia Liu and Umar Al-Sheikh have contributed equally to this work.

Lijun Kang

kanglijun@zju.edu.cn

1 Department of Neurobiology and Department of Neurosurgery of the First Affiliated Hospital, Zhejiang University School of Medicine, Hangzhou 310053, China

2 NHC and CAMS Key Laboratory of Medical Neurobiology, MOE Frontier Science Center for Brain Research and BrainMachine Integration, School of Brain Science and Brain Medicine, Zhejiang University, Hangzhou 310053, China

3 Department of Gastroenterology, Sir Run Run Shaw Hospital, Zhejiang University School of Medicine, Hangzhou 310016, China

4 Department of Human Sciences and Psychology, University of South Africa (UNISA), Pretoria 0003, South Africa sensitive glutamate receptor GLR-3. Thus, we propose the polymodal functionality of OLL neurons in mechanosensation and cold sensation.

Keywords Polymodal sensory neuron $\cdot$ Mechanosensation - Thermosensation - Sodium channel $\cdot$ Cold receptor . OLL neurons

\section{Introduction}

The ability to detect sensory cues is innate to living organisms to produce appropriate behavioral and physiological responses for survival [1]. Specialized neurons are often polymodal, responding to ambient stimuli in the form of chemicals, temperature, and touch intensity [1,2]. In mammals, nociceptive neurons located in the dorsal root ganglion and trigeminal ganglion are activated by noxious chemicals, extreme temperatures, and mechanical stimuli [3]. Drosophila class IV da neurons are well-known polymodal neurons, which can detect diverse forms of stimuli, such as thermal, mechanical, proprioceptive, and light stimuli [4-7]. The nematode Caenorhabditis elegans stands as an excellent model for dissecting sensory mechanisms with its 302 confirmed hermaphrodite neurons, and numerous behavioral analyses can be readily performed in the small and rapidly-growing worm. Neurons in C. elegans are often multifunctional, involved in complex behaviors through neuronal circuits and signaling molecules [1, 8-10].

The C. elegans outer labial lateral (OLL) sensilla sensory neurons negatively regulate pathogen avoidance behavior via HECW-1 to undergo adaptive changes in response to microbial pathogens. Laser ablation of OLL neurons enhances pathogen-avoidance behavior, 
suggesting that they play an important role in conserved innate immune responses $[11,12]$. In addition, nose touchdefects were also reported from animals in which OLL was ablated genetically [11]. However, the nature of OLL neurons' responses to environmental stimuli is yet to be determined at the cellular level, with the underlying molecular mechanisms still elusive.

In this study, we investigated the sensory responses of OLL neurons using miscellaneous stimuli, $\mathrm{Ca}^{2+}$ imaging, and electrophysiological recordings. By methodological micro-dissection of the nose tip, OLL neurons were exposed and responded to mechanical stimulation through a novel $\mathrm{Na}^{+}$conductance channel. However, we ruled out degenerin/epithelial $\mathrm{Na}^{+}$channel (DEG/ENaC) family proteins and found that this mysterious channel is amiloride-insensitive, and responsible for the mechanotransduction of OLL neurons in C. elegans. Apart from mechanotransduction, we also revealed that OLL neurons responded to cold stimulation cell-autonomously but not via the typical TRPA-1 channel $[13,14]$. Therefore, we provide an avenue for the molecular dissection of sensory modalities in OLL neurons.

\section{Materials and Methods}

\section{Strains}

The $C$. elegans strains were raised on NGM plates seeded with OP50 bacteria at $20^{\circ} \mathrm{C}$. We generated the transgenic strain kanEx1200[Pser-2d::GCaMP6s + Pser-2d:: $m$ Cherry + Plin-44::gfp] by micro-injection, to detect intracellular $\mathrm{Ca}^{2+}$ activity in OLL neurons. The mutant strains used in this study were unc-13(e51), unc-31(e928), trpa-1(ok999), deg-1(u38), and mec-10(e1515).

\section{Molecular Biology}

The ser-2d promoter [15] was amplified by PCR using the primers $5^{\prime}$-acgctaacaacttggacatgcttgttctagtgatc- $3^{\prime}$ and $5^{\prime}$ tttgggtcctttggccattatgtgttgtgatgtcacaa- $3^{\prime}$. A 4.1-kb fragment generated from Bristol N2 genomic DNA was cloned into the PBS77 vector using In-fusion technology (Vazyme). We injected the N2 strain with Pser-2d::GCaMP6s at $80 \mathrm{ng} / \mu \mathrm{L}$ and Pser-2d::mCherry at $50 \mathrm{ng} / \mu \mathrm{L}$, together with $20 \mathrm{ng} / \mu \mathrm{L}$ Plin-44::gfp as a co-injection marker.

\section{Calcium Imaging}

Worms were glued to a glass-bottom cell culture dish covered with a thin layer of 5\% agarose then immersed in bath solution. This solution consisted of (in mmol/L) 145 $\mathrm{NaCl}, 2.5 \mathrm{KCl}, 5 \mathrm{CaCl}_{2}, 1 \mathrm{MgCl}_{2}, 20$ glucose, adjusted to
pH 7.3. We used an SC-20 Dual In-line Solution Heater/ Cooler (Warner Instruments) to precisely regulate the temperature of the bath. $\mathrm{Ca}^{2+}$ imaging was carried out on an Olympus IX83 inverted microscope under a $40 \times$ objective with Olympus cellSens software. The temperature-stimulated $\mathrm{Ca}^{2+}$ imaging system was as described previously $[16,17]$.

\section{Touch-Stimulated Calcium Imaging}

The touch-stimulated $\mathrm{Ca}^{2+}$ imaging protocol was as previously described $[10,16,18]$. Briefly, worms were glued on a coverslip and immersed in bath solution. Touch stimuli were delivered to OLL neurons using about $1 \mu \mathrm{m}$ borosilicate glass capillary needle on a micromanipulator (Sutter). The needle was placed near the worm's nose and Patchmaster software (HEKA Elektronik) was used to control the micromanipulator. When executing the "touch" command, the needle moved forward and touched the worm's nose for $500 \mathrm{~ms}$ then returned to the original position. $\mathrm{Ca}^{2+}$ imaging was recorded on an Olympus BX51WI upright microscope under a $60 \times$ objective with Macro-manager software. The bath solution consisted of (in mmol/L) $145 \mathrm{NaCl}, 2.5 \mathrm{KCl}, 5 \mathrm{CaCl}_{2}, 1 \mathrm{MgCl}_{2}, 20$ glucose, adjusted to $\mathrm{pH}$ 7.3. In $\mathrm{Na}^{+}$-deprived bath solution, an equimolar concentration of N-methyl-D-glucamine chloride (NMDG-Cl) was substituted for $\mathrm{NaCl}$.

\section{Electrophysiology}

Whole-cell patch clamp recordings were carried on an Olympus BX51WI upright microscope under a $60 \times$ objective with an EPC-10 amplifier and Patchmaster software as previously described [19]. Briefly, a glass stimulus probe driven by a Piezo actuator was mounted on a micromanipulator and triggered by an amplifier. Mechanical stimulation continued for $500 \mathrm{~ms}$. Worms were glued to a Sylgard-coated coverslip covered with bath solution, and a small piece of cuticle in the head was cut and pinned to the coverslip to expose the cell bodies of OLL neurons. To identify OLL neurons, the fluorescent protein marker mCherry-fused ser-2d plasmid was injected before dissection. Recording pipettes were pulled on a micropipette puller P-1000 (Sutter). The bath solution contained (in $\mathrm{mmol} / \mathrm{L}) 145 \mathrm{NaCl}, 2.5 \mathrm{KCl}, 5 \mathrm{CaCl}_{2}, 1 \mathrm{MgCl}_{2}$, and 20 glucose (325-335 mOsm, $\mathrm{pH}$ adjusted to 7.3). The intracellular solution consisted of (in mmol/L) 145 Csgluconate, $5 \mathrm{MgCl}_{2}$, 5 EGTA, $0.25 \mathrm{CaCl}_{2}, 10$ HEPES, 10 glucose, $5 \mathrm{Na}_{2} \mathrm{ATP}$, and $0.5 \mathrm{Na}_{2} \mathrm{GTP}$ (315-325 mOsm, pH adjusted to 7.2). The membrane potential was clamped at $-70 \mathrm{mV}$. The DEG/ENaC channel blocker amiloride was dissolved in the bath to a final concentration of $400 \mu \mathrm{mol} /$ L. 


\section{Primary Cell Culture}

The protocol for $C$. elegans primary cell culture was as described previously [20]. In brief, day 2 adult (D2) worms were lysed to enrich the eggs (lysis solution: $5 \mathrm{~mL}$ fresh bleach, $1.25 \mathrm{~mL} 10 \mathrm{~mol} / \mathrm{L} \mathrm{NaOH}$, and $18.5 \mathrm{~mL}$ sterile $\mathrm{H}_{2} \mathrm{O}$ ). Eggs were digested with $2 \mathrm{mg} / \mathrm{mL}$ chitinase (Sigma, catalog no. C6137) and dissociated into single cells. Then the cells were implanted on glass-bottomed cell-culture dishes coated with peanut lectin (Sigma, catalog no. L0881) at a suitable cell concentration. The cells were cultured in L-15 medium (Invitrogen, catalog no. 21083-027) with $10 \%(\mathrm{v} / \mathrm{v})$ heat-inactivated fetal bovine serum (Invitrogen, catalog no. 10082-139), $50 \mathrm{U} / \mathrm{mL}$ penicillin, and $50 \mathrm{mg} / \mathrm{mL}$ streptomycin (Invitrogen, cata$\log$ no. 15140-122). After two days in culture, $\mathrm{Ca}^{2+}$ imaging experiments were performed. The isolated OLL neurons were recognized by expression of Pser$2 d::$ mcherry as well as Pser-2d::GCaMP6s. It has been reported that the posterior ventral dorsal (PVD) neurons sense cold via TRPA-1 channels and detect touch through ENaC channels [21, 22]. Given that PVD and OLL neurons share the same ser-2d promoter, we isolated cells of the trpa-1 mutant strain for temperature-stimulated $\mathrm{Ca}^{2+}$ imaging to exclude PVD neurons. For touch-stimulated $\mathrm{Ca}^{2+}$ imaging in isolated OLL neurons, we immersed the cells in bath solution containing $400 \mu \mathrm{mol} / \mathrm{L}$ amiloride to rule out PVD neurons.

\section{Statistical Analysis}

Data analysis was performed using ImageJ and GraphPad Prism 6. All data are presented as the mean \pm SEM and unpaired two-tailed Student's $t$-test was used to compare data sets. If the data were not normally distributed, the Wilcoxon test was used. $P<0.05$ was considered to be statistically significant.

\section{Results}

\section{OLL Neurons Respond to Touch and Cold}

OLL neurons (OLLL and OLLR) are neurons of the outer labial lateral sensilla with the axis cylinder processes extending to the tip of the worm's nose (Fig. 1A, B). To explore the response spectrum of OLL neurons, we generated a transgenic strain expressing the $\mathrm{Ca}^{2+}$ indicator protein GCaMP6s and a red fluorescent protein mCherry under the control of the ser- $2 d$ promoter $[15,23]$. The worms expressed GCaMP6s and mCherry in OLL neurons and another class of sensory neurons, the phasmid ventral cord (PVD) neurons (Fig. 1A). We then performed several sensory stimuli tests including the use of odorants, salt, warm and cold temperatures, and nose-touch that OLL neurons may detect. We found that mechanical stimulation evoked fast $\mathrm{Ca}^{2+}$ transients in OLL neurons (Fig. 1C, D). Furthermore, OLL neurons exhibited rapid and robust $\mathrm{Ca}^{2+}$ transients to cold stimulation when the buffer temperature was decreased from $27^{\circ} \mathrm{C}$ to $10^{\circ} \mathrm{C}$ (Fig. 1E, F). As such, OLL neurons respond to mechanical stimulation as well as cold stimulation. We also found that the repulsive odor 1-octanol $[24,25]\left(1 / 1000\right.$ in bath solution) induced $\mathrm{Ca}^{2+}$ increases in OLL neurons. However, the latency of these increases was extremely long ( $>30 \mathrm{~s}$ ) (Fig. 1G, J), indicating that OLL neurons respond to 1-octanol in a non-cell-autonomous manner. Diacetyl $(1 / 1000$ in bath solution), which is attractive to worms $[24,26]$, did not evoke detectable $\mathrm{Ca}^{2+}$ transients in OLL neurons (Fig. $1 \mathrm{H}$, J). In addition, high salt $(200 \mathrm{mmol} / \mathrm{L} \mathrm{NaCl})$ and warm stimulation did not evoke $\mathrm{Ca}^{2+}$ responses in OLL neurons (Fig. 1H-J).

\section{The Amplitude of Calcium Responses in OLL Neu- rons Depends on the Strength of Mechanical Stimuli}

To determine the threshold of mechanical stimulus-evoked $\mathrm{Ca}^{2+}$ responses in OLL neurons, we applied stimuli of varying intensities to the nose tip. We used a glass probe driven by a Piezo actuator to deliver a mechanical stimulus with a defined intensity to the cilium of OLL neurons. The results demonstrated that the increased touch-evoked $\mathrm{Ca}^{2+}$ responses depend on a significant increase of stimulus intensity, and a displacement of $15 \mu \mathrm{m}$ was sufficient to induce a $\mathrm{Ca}^{2+}$ response (Fig. 2A, B). Consequently, the $\mathrm{Ca}^{2+}$ responses were rapid and robust when the stimulus displacement was up to $20 \mu \mathrm{m}$ (Fig. 2A, B). Considering that harsh touch may cause irreversible deformation and damage, we refrained from displacements $>20 \mu \mathrm{m}$. We then applied a stimulus of $20 \mu \mathrm{m}$ displacement to the subsequent $\mathrm{Ca}^{2+}$ imaging experiments.

\section{OLL Neurons Sense Mechanical Stimulation Cell- Autonomously Through Sodium Channels}

OLL neurons responded to mechanical stimulation rapidly and robustly (Fig. 2A), indicating that they function as primary sensory neurons for mechanosensation. To further verify this hypothesis, we measured their touch-induced $\mathrm{Ca}^{2+}$ responses in unc-13 and unc-31 mutants. The unc-13 gene encodes UNC-13 protein, a Munc13 homolog in $C$. elegans, which is required for the release of neurotransmitters from synaptic vesicles $[27,28]$. The unc-31 gene encodes the mammalian ortholog CAPS in $C$. elegans that is essential for the release of neuropeptide from dense core vesicles [29]. The mechanically-evoked $\mathrm{Ca}^{2+}$ transients of 
A

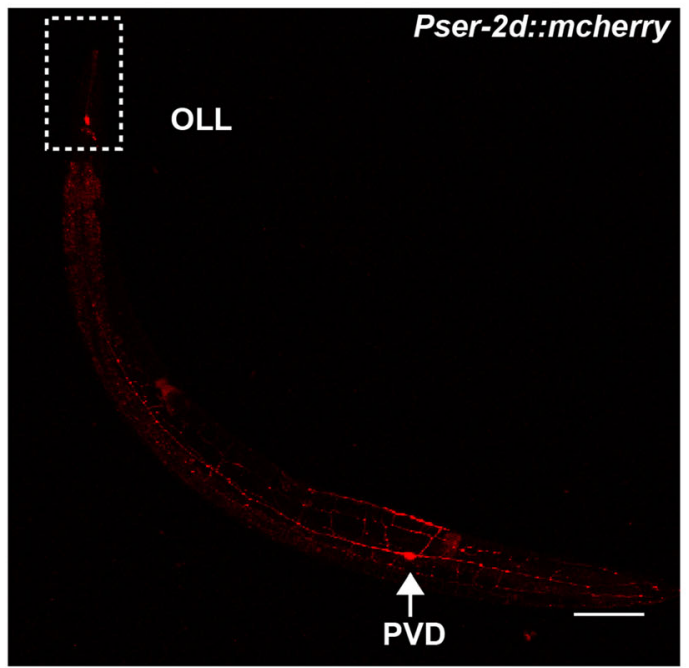

C

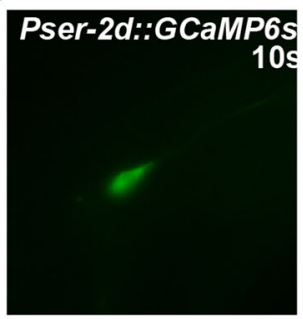

E
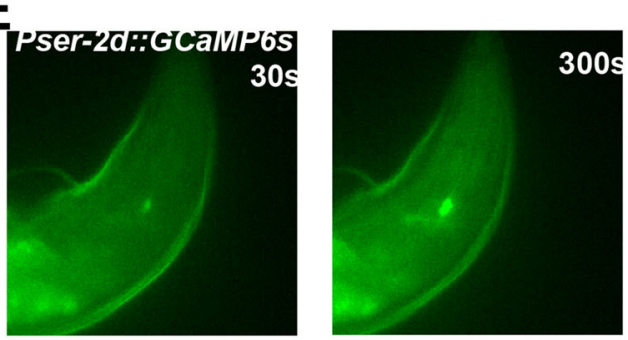

300 s

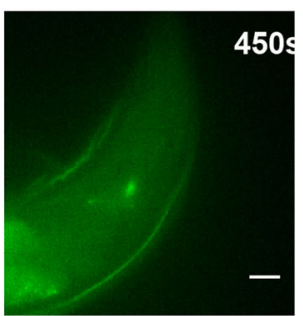

B
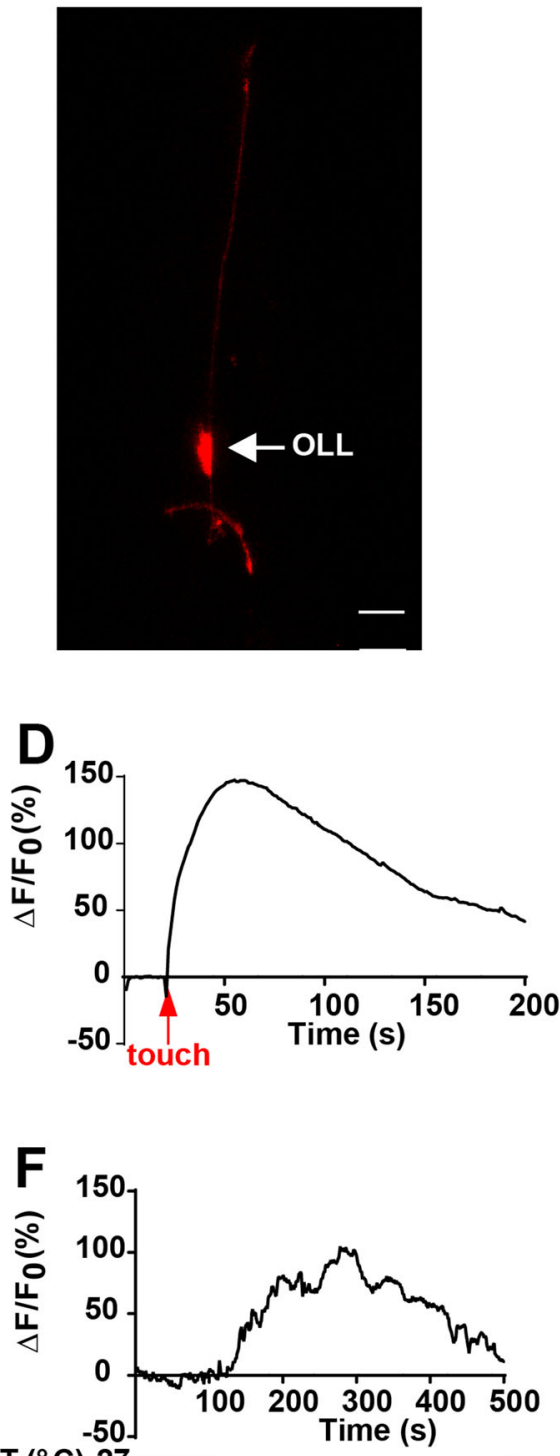

$\mathrm{T}\left({ }^{\circ} \mathrm{C}\right) 27$

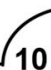

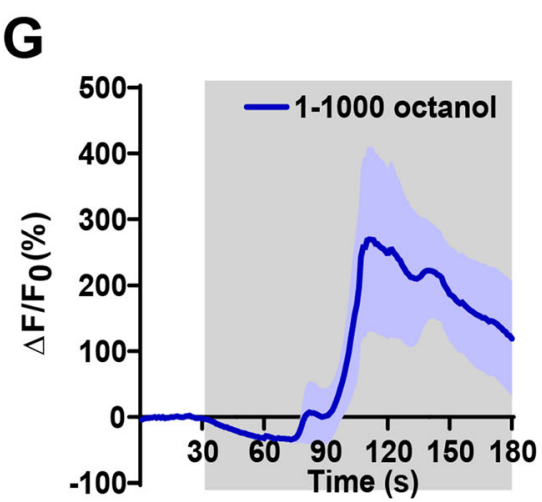

- 1:1000 diacetyl
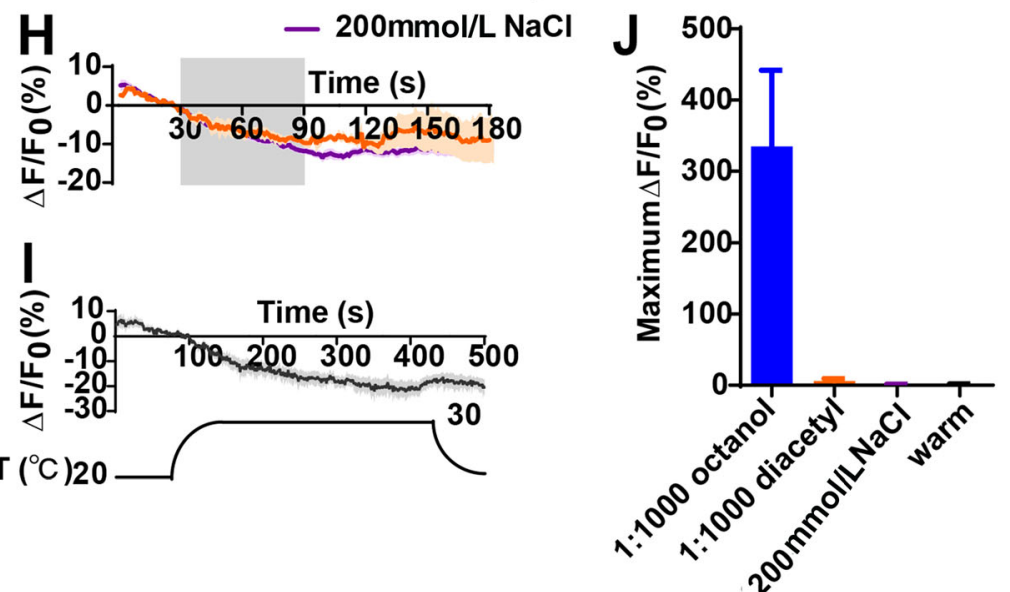
4Fig. 1 The response spectrum of $C$. elegans OLL neurons. A Expression pattern of ser- $2 d$ reporter gene fusion. Pser-2d::mCherry exclusively expresses in OLL neurons and PVD neurons (scale bar, $100 \mu \mathrm{m})$. B OLL labeled with Pser-2d::mCherry marker. C, D Representative time-lapse images of $\mathrm{Ca}^{2+}$ responses based on GCaMP6s (C) and soma fluorescence changes (D) from an OLL neuron in response to nose touch. A glass probe driven by a Piezo actuator is used to deliver a mechanical stimulus with a defined displacement towards the cilium of the OLL neuron. The stimulus displacement is $20 \mu \mathrm{m}$ for $500 \mathrm{~ms}$. Red arrow, time of mechanical stimulation. E, F Representative time-lapse images of $\mathrm{Ca}^{2+}$ responses based on GCaMP6s (E) and soma fluorescence changes (F) from an OLL neuron. The initial temperature of the recording buffer is $27^{\circ} \mathrm{C}$, and the lowest temperature is $10^{\circ} \mathrm{C}$. Cool-down is initiated at $100 \mathrm{~s}$, then heated back to $27^{\circ} \mathrm{C}$ after $5 \mathrm{~min}$ (scale bars, $10 \mu \mathrm{m}$ in $\mathbf{B}, \mathbf{C}, \mathbf{E}$ ). $\mathbf{G}$ The repulsive odor 1 -octanol $(1: 1000)$ induces $\mathrm{Ca}^{2+}$ responses in OLL neurons. Note that the delay of 1 -octanol evoked $\mathrm{Ca}^{2+}$ transients is quite long (gray rectangle, duration of administration). $\mathbf{H}$ The attractive odor diacetyl $(1: 1000)$ and $200 \mathrm{mmol} / \mathrm{L} \mathrm{NaCl}$ does not cause a $\mathrm{Ca}^{2+}$ response in OLL neurons (gray rectangle, duration of administration). I Warm stimulation-induced $\mathrm{Ca}^{2+}$ responses in OLL neurons. The initial temperature of the recording buffer is $20^{\circ} \mathrm{C}$, and the highest temperature is $30^{\circ} \mathrm{C}$. Heating is initiated at $100 \mathrm{~s}$, then back to $20^{\circ} \mathrm{C}$ after $5 \mathrm{~min}$. J Maximum $\Delta \mathrm{F} / \mathrm{F}_{0}$ changes $(\mathbf{D})$ of odorants, salt, and warm stimulation-induced $\mathrm{Ca}^{2+}$ responses in OLL neurons.

OLL neurons in both $u n c-13$ and $u n c-31$ mutant worms did not differ from wild-type worms (Fig. 2C, D). These results support the hypothesis that OLL neurons detect mechanical stimulation cell-autonomously.

To further confirm that OLL neurons directly detect mechanical stimulation, we performed $\mathrm{Ca}^{2+}$ imaging in isolated OLL neurons to avoid cell-to-cell communication. Remarkably, mechanical stimulation induced $\mathrm{Ca}^{2+}$ elevation in the isolated neurons with a displacement of $3 \mu \mathrm{m}$ (Fig. 2E, F), further supporting the hypothesis.

To explore the molecular basis of the mechanosensation of OLL neurons, we further examined their touch-induced $\mathrm{Ca}^{2+}$ responses in mechanotransduction-related candidate mutants. So far, DEG/ENaC channels such as MEC-4, MEC-10, and DEG-1, the transient receptor potential (TRP) channel protein TRP-4, and the transmembrane channel-like protein 1 (TMC-1) have been identified as mechano-gated channels in C. elegans [30-33]. Given that all these proteins as well as the mechano-gated Piezo channels are cation channels [31, 32, 34-36], we investigated whether extracellular $\mathrm{Na}^{+}$might be responsible for the mechanotransduction of OLL neurons. We performed $\mathrm{Ca}^{2+}$ imaging by replacing $\mathrm{NaCl}$ with $\mathrm{NMDG}-\mathrm{Cl}$ in the bath. Remarkably, $20 \mu \mathrm{m}$ displacement-induced $\mathrm{Ca}^{2+}$ responses in OLL were largely reduced in the $\mathrm{Na}^{+}$-free bath than that in normal solution (Fig. 2E, F). These results suggest that cation channels mediate the mechanosensation of OLL neurons. Since the DEG/ENaC protein MEC-4 is known as a mechanoreceptor which is exclusively expressed in gentle touch neurons such as ALM and
PLM [37, 38], we then tested the touch-induced $\mathrm{Ca}^{2+}$ transients of OLL neurons in deg-1 and mec-10 mutants. Both mutant worms displayed no significant difference in the nose touch-evoked $\mathrm{Ca}^{2+}$ response in OLL neurons from that of the wild-type (Fig. 2C, D). Nevertheless, the deg-1 and mec-10 mutants showed modest inhibition of the touch-induced $\mathrm{Ca}^{2+}$ responses. Thus, our data do not rule out the possibility that DEG-1 and MEC-10 may be involved in the mechanosensation of OLL neurons. Overall, these findings suggest that OLL neurons detect mechanical stimulation through cation channels.

\section{Mechanotransduction of OLL Neurons Might be Carried by a Novel Sodium Conductance Channel}

If OLL neurons do function as mechanoreceptors, a mechanoreceptor current (MRC) responding to mechanical stimulation should be detected by whole-cell patch clamp recording in intact worms [31]. We then performed patchclamp recording in OLL neurons. Briefly, the cell body was carefully exposed to a recording pipette by micro-dissection while keeping the nose tip in perfect condition (Fig. 3A). Strikingly, mechanical force evoked an MRC (Fig. 3B-D). The 10-90\% rise time and the 10-90\% decay time of the MRC were $<25 \mathrm{~ms}$ and $1 \mathrm{~s}$, respectively (Fig. 3E, F). Thus, the MRC was fast and transient. It should be noted that the nose touch-evoked MRC had a very short latency $(1.5 \pm 0.3 \mathrm{~ms}, 12 \mu \mathrm{m}$ displacement, $n=4)$. As the fastest known intracellular second messenger signaling takes more than $5 \mathrm{~ms}$ [31, 39-41], it is highly improbable that a second messenger indirectly activates MRCs in OLL neurons. Moreover, we found that the amplitude and latency of MRCs was dependent on the strength of mechanical stimulation (Fig. 3C, D). When a displacement of $15 \mu \mathrm{m}$ was applied, the MRC latency approached $1 \mathrm{~ms}(0.8 \pm 0.2 \mathrm{~ms}, n=6)$. Besides, a displacement of $4 \mu \mathrm{m}$ was able to evoke a small MRC (Fig. 3C, D). The MRC threshold was much lower than that of mechano-evoked $\mathrm{Ca}^{2+}$ transients (Figs. 2A, B; 3C, D), perhaps because the depolarization induced by a small MRC was insufficient to open the voltage-gated $\mathrm{Ca}^{2+}$ channels.

To further test the biophysical properties of the MRC in OLL neurons, we recorded the current-voltage relationships (I-V curves) of MRCs. The reversal potential of the MRC was $53 \mathrm{mV}$, which is similar to the reversal potential of the $\mathrm{Na}^{+}$channel conductance but distinct from that of mechano-gated non-selective cation channels such as TRP4, TMC, and Piezo [31, 32, 34, 35, 42] (Fig. 4A, B). Furthermore, the MRC induced by nose touch with $12 \mu \mathrm{m}$ displacement was abolished in the $\mathrm{Na}^{+}$-deprived bath (Fig. 4C, D). According to previous reports, all known 
A

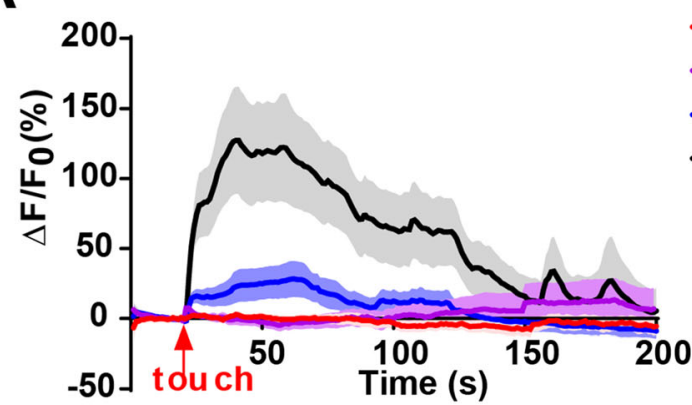

$-5 \mu \mathrm{m}$

B

$-10 \mu \mathrm{m}$

$-15 \mu \mathrm{m}$

$-20 \mu \mathrm{m}$

C

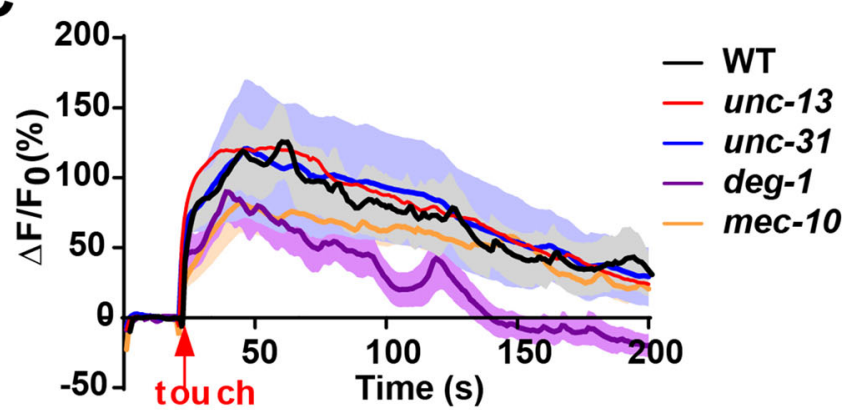

E

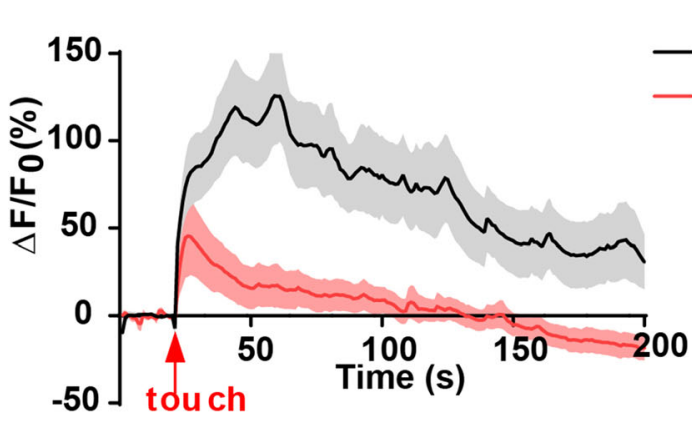

G

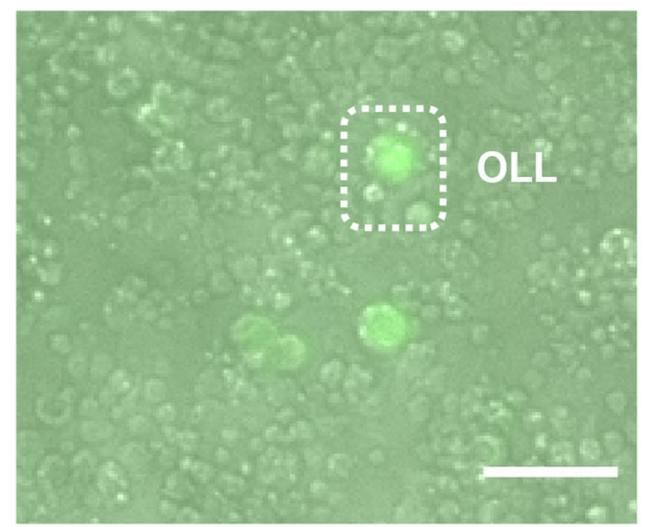

H

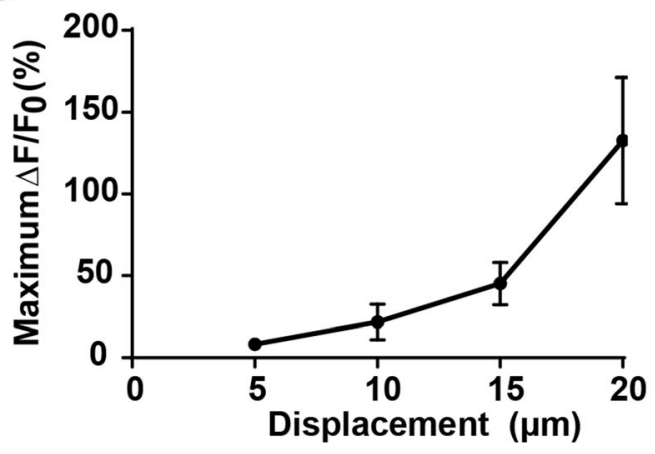

D
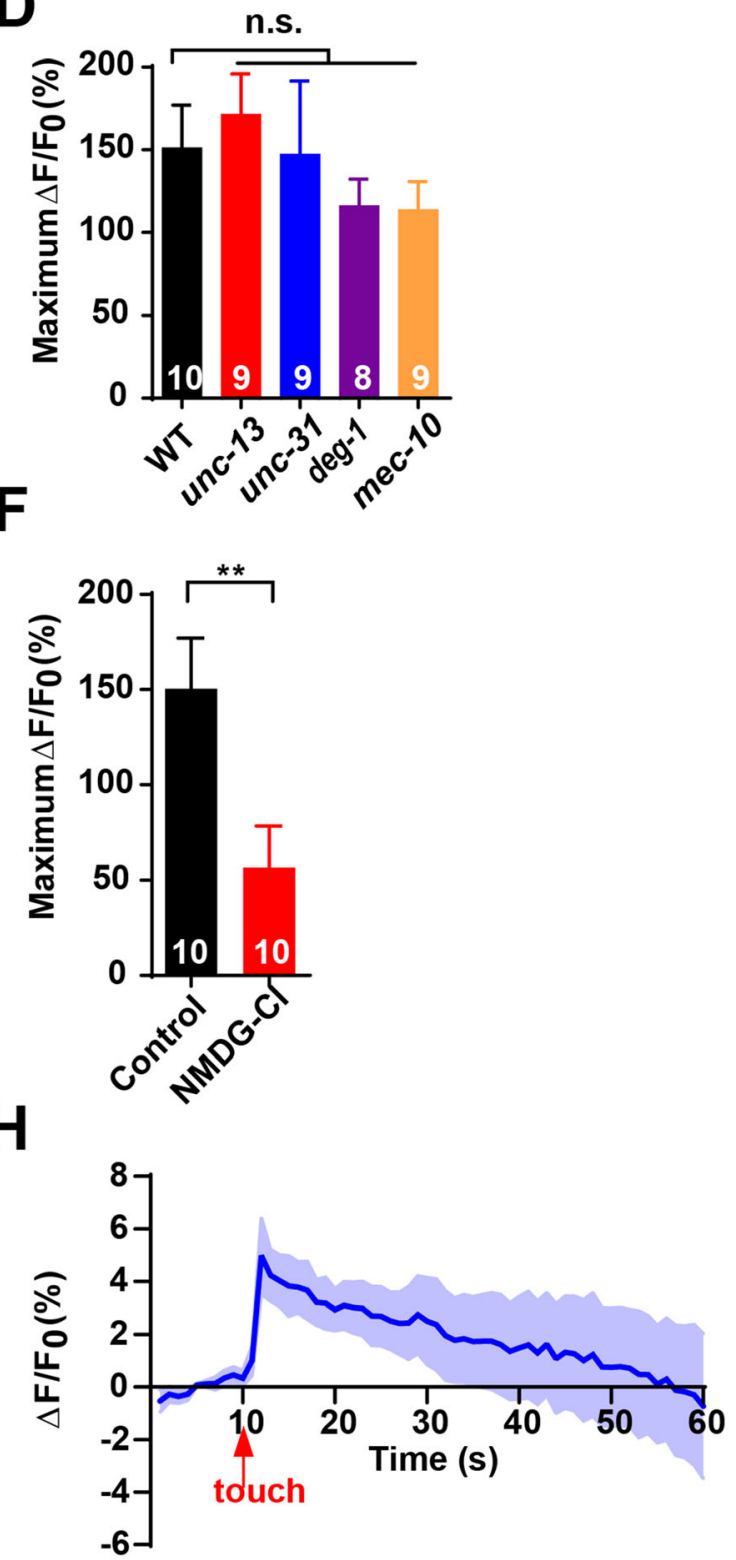
4Fig. 2 OLL neurons respond to mechanical stimulation in a cellautonomous manner. $\mathbf{A}, \mathbf{B} \mathrm{Ca}^{2+}$ responses $(\mathbf{A})$ and maximum $\Delta \mathrm{F} / \mathrm{F}_{0}$ changes (B) induced by mechanical stimulation. Displacements of $5 \mu \mathrm{m}, 10 \mu \mathrm{m}, 15 \mu \mathrm{m}$, and $20 \mu \mathrm{m}$ are tested. Considering that harsh touch may cause irreversible deformation and damage, we did not use displacements $>20 \mu \mathrm{m}$. The $n$ values for the $5 \mu \mathrm{m}, 10 \mu \mathrm{m}, 15 \mu \mathrm{m}$, $20 \mu \mathrm{m}$ displacement groups were $10,10,14$, and 9 , respectively. C, D $\mathrm{Ca}^{2+}$ responses $(\mathbf{C})$ and maximum $\Delta \mathrm{F} / \mathrm{F}_{0}$ changes $(\mathbf{D})$ induced by mechanical stimulation in OLL neurons of wild type $(n=10)$, unc-13 mutants $(n=9), u n c-31$ mutants $(n=9)$, deg- 1 mutants $(n=8)$, and mec-10 mutants $(n=9)$. The stimulus displacement is $20 \mu \mathrm{m}$. E, $\mathbf{F}$ $\mathrm{Ca}^{2+}$ responses $(\mathbf{E})$ and maximum $\Delta \mathrm{F} / \mathrm{F}_{0}$ changes $(\mathbf{F})$ induced by mechanical stimulation. Worms of the experimental group are immersed in perfusate in which NMDG-Cl replaces $\mathrm{NaCl}$. The stimulus displacement was $20 \mu \mathrm{m} . n=10$ animals per condition. G Image of a culture of isolated $C$. elegans embryonic cells. Isolated OLL neurons are indicated by the expression of GCaMP6s (scale bar, $20 \mu \mathrm{m})$. H Mechanical stimulation-evoked $\mathrm{Ca}^{2+}$ responses in isolated OLL neurons. To rule out PVD neurons, we immersed the cells in $400 \mu \mathrm{mol} / \mathrm{L}$ amiloride. The stimulus displacement was $3 \mu \mathrm{m} . n=6$. Error bars indicate SEM; n.s., not significant, $P>0.05$; $* * P<0.01$.

mechano-gated $\mathrm{Na}^{+}$channels belong to the DEG/ENaC family of proteins, which can be effectively blocked by amiloride [31, 38, 40]. However, upon treatment with $400 \mu \mathrm{mol} / \mathrm{L}$ amiloride, the MRCs in OLL neurons were indistinguishable from those in control worms, suggesting that the $\mathrm{ENaC}$ channel is not the mechanoreceptor channel in OLL neurons (Fig. 4C, D). These results support the conclusion that the MRCs in OLL neurons are carried by a novel $\mathrm{Na}^{+}$conductance channel.

\section{OLL Neurons Respond to Cold Temperatures but not Via TRPA-1 Channels}

We next explored the molecular mechanism of responses in OLL neurons activated by cold stimulation. First, we investigated whether OLL neurons can sense cold stimulation cell-autonomously. The cold-evoked $\mathrm{Ca}^{2+}$ transients in unc-13 and unc-31 mutants were normal compared to the wild-type (Fig. 5A, B), suggesting that OLL neurons act as primary sensory neurons that can sense cold stimulation cell-autonomously. We then performed $\mathrm{Ca}^{2+}$ imaging in isolated OLL neurons to confirm that they directly respond to cold stimulation. Interestingly, the isolated OLL neurons responded to cold stimulation, supporting the hypothesis that OLL neurons mediate cold sensation in a cellautonomous manner (Fig. 5C).

Since OLL neurons directly sense cold, cold receptors must be present in them. Three cold receptors - TRPM8, TRPA1, and GLR-3 - have been identified in mammals $[13,16,43]$. TRPM8 does not have evolutionarily-conserved expression in C. elegans [44] and GLR-3 does not seem to be expressed in OLL neurons (https://cengen. shinyapps.io/SCeNGEA/). In this case, since TRPA-1 is a known cold-sensitive receptor in C. elegans [22, 45], we enquired whether TRPA-1 was involved in the cold sensitivity of OLL neurons. Interestingly, the cold-induced $\mathrm{Ca}^{2+}$ transients were unaffected in trpa- 1 mutants compared to wild-type worms (Fig. 6A, B), suggesting that the cold receptor is not TRPA-1. Hence, there are other unknown cold-sensitive receptors of OLL neurons that remain to be revealed.

\section{Discussion}

All animals are endowed with the highly-conserved ability to detect mechanical stimulation in the form of touch, nociception, and proprioception [1]. C. elegans was the first model organism in which unbiased forward genetic screening was used to identify the genes contributing to mechanosensation [46, 47]. Over the years, several polymodal sensory neurons have been identified in the nematode. Polymodal sensory neurons are a specific class of sensory neurons that can detect distinct sensory stimuli. In contrast, neurons that only recognize a single stimulus are unimodal sensory neurons [48]. Nociceptive sensory neurons are typically polymodal with remarkable ability to sense a wide variety of aversive stimuli including physical and chemical stimuli, and to transduce them into diverse degrees and modalities of pain signals [49]. The bilateral pair of ASH neurons (amphid neurons with single ciliated endings) sense chemical, mechanical, and osmotic stimuli to mediate backward locomotion for self-defense [10, 48, 50, 51]. The PVD neurons detect noxious cold temperatures, harsh touch, and are involved in proprioception [21, 22]. The PHA/PHB neurons respond to several aversive stimuli, including chemical, mechanical, and osmotic stimuli [10]. Other sensory neurons are under scrutiny to decipher the molecular basis of the sensory processes and the multimodality.

\section{OLL Neurons are Novel Polymodal Sensory Neurons}

Previous studies using the electron microscopy reconstruction found that OLL neurons have a single dendrite. The cilia of OLL neurons traverse through a channel created by socket cells and the end is finally embedded in the amphid subcuticle [8]. Chang et al. reported nose touch defects from animals in which the OLL neurons were genetically ablated, suggesting that they are involved in mechanosensation [11]. Nevertheless, the molecular mechanism of this mechanosensation remained elusive. In the present study, using $\mathrm{Ca}^{2+}$ imaging and patch-clamp recording, we revealed nose touch-evoked $\mathrm{Ca}^{2+}$ increases and currents in OLL neurons in a cell-autonomous manner. 


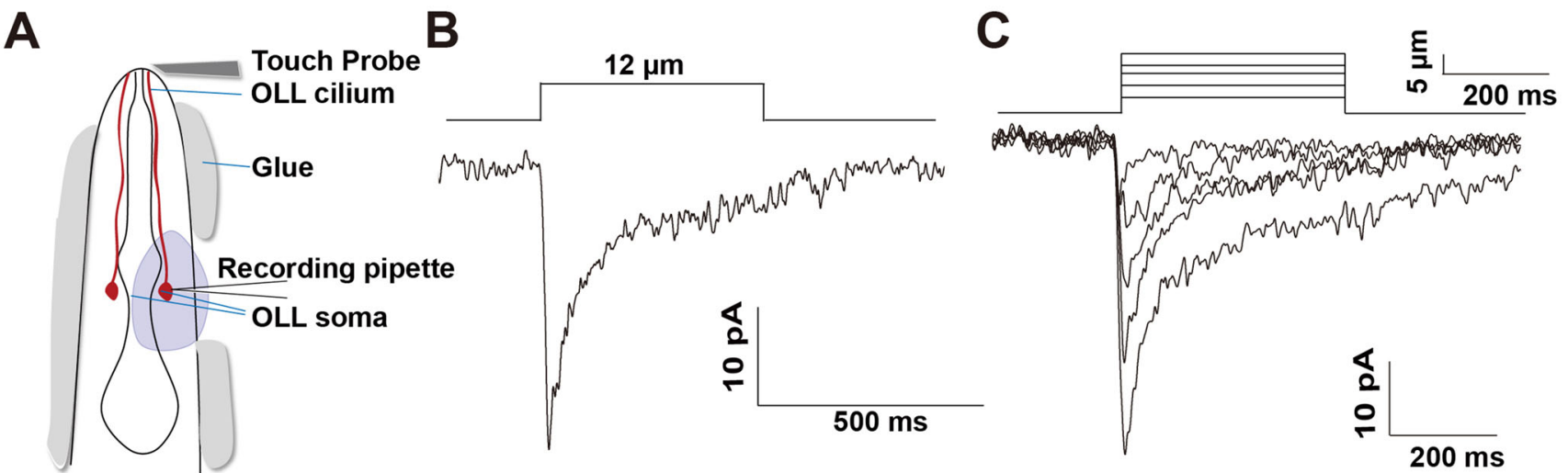

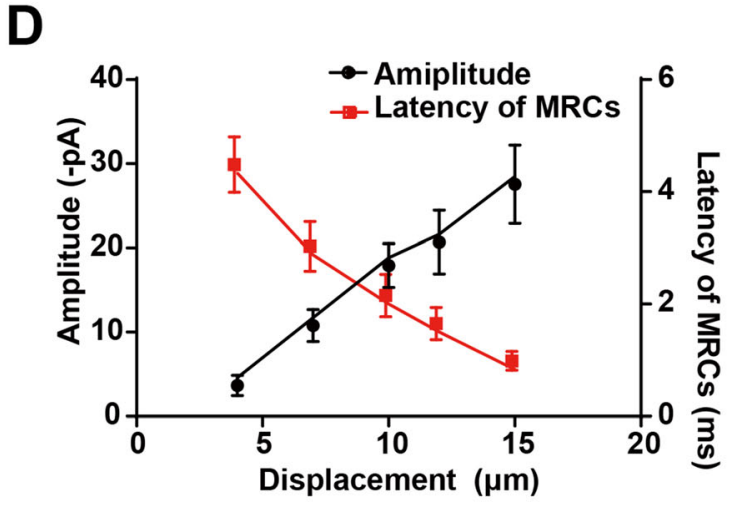

Fig. 3 Recordings of mechanoreceptor current (MRC) in OLL neurons in situ. A Schematic of MRC recording in OLL neurons from a dissected worm. A glass probe (about $10 \mu \mathrm{m}$ in diameter) driven by a Piezo actuator delivers mechanical stimulation to the cilium of OLL neurons. B Representative MRCs in OLL neurons respond to mechanical stimulation with a displacement of $12 \mu \mathrm{m}$. Cell membrane potential is voltage-clamped at $-70 \mathrm{mV}$. C Sample traces of MRCs in OLL neurons recorded in response to $4 \mu \mathrm{m}, 7 \mu \mathrm{m}, 10 \mu \mathrm{m}$, $12 \mu \mathrm{m}$, and $15 \mu \mathrm{m}$ displacement. Cell membrane potential is voltageclamped at $-70 \mathrm{mV}$. D The amplitude and latency of MRCs in OLL neurons are dependent on the strength of stimulation. Note that the latency is close to $1 \mathrm{~ms}$ when the displacement is $15 \mu \mathrm{m}$. Cell

Collectively, OLL neurons are involved in mechanosensation. Intriguingly, OLL neurons are also involved in detecting cold stimulation, which has not been reported before. The behaviors of cold temperature perception, including innocuous cool sensation, noxious cold sensation, positive and negative thermotactic behaviors, and temperature-related memory and aging, are quite complicated $[1,16,45]$. Due to the complexity of this temperature-coding scheme, it is often difficult to identify the temperature behavioral output for a specific neuron. At this stage, we have not observed any obvious behavioral output of OLL neurons in response to cold stimulation. Future studies are needed to reveal these details. Nevertheless, our $\mathrm{Ca}^{2+}$ imaging experiments conducted both in vivo and in vitro clearly showed that OLL neurons responded to cold stimulation in a cell-autonomous manner, supporting the conclusion that they are cold-sensing cells. It is thus clear
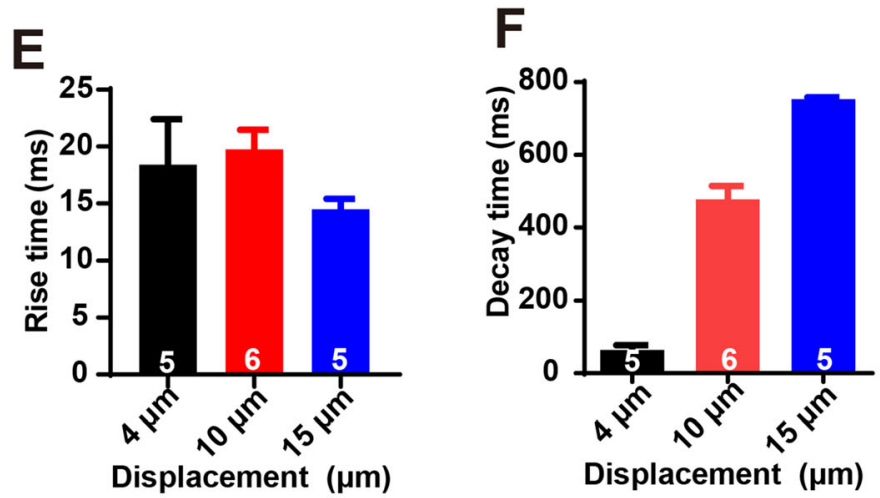

membrane potential is voltage-clamped at $-70 \mathrm{mV}$. The $n$ values for the $4 \mu \mathrm{m}, 7 \mu \mathrm{m}, 10 \mu \mathrm{m}, 12 \mu \mathrm{m}$, and $15 \mu \mathrm{m}$ displacement groups are $8,8,7,4$, and 6, respectively. $\mathbf{E}$ The $10 \%-90 \%$ rise time of MRCs in OLL neurons. Note that the rise time is $<25 \mathrm{~ms}$. The cell membrane potential is voltage-clamped at $-70 \mathrm{mV}$. The $n$ values for the $4 \mu \mathrm{m}$, $10 \mu \mathrm{m}$, and $15 \mu \mathrm{m}$ displacement groups are 5, 6, and 5, respectively. F The 10\%-90\% decay time of MRCs in OLL neurons. Note that the decay time is $<1 \mathrm{~s}$. The cell membrane potential is voltage-clamped at $-70 \mathrm{mV}$. The $n$ values for the $4 \mu \mathrm{m}, 10 \mu \mathrm{m}$, and $15 \mu \mathrm{m}$ displacement groups are 5, 6, and 5, respectively. Error bars indicate SEM.

that OLL neurons act as polymodal sensory neurons functioning in mechanotransduction and cold transduction.

\section{A Novel Sodium-Sensitive Channel in Mechanotransduction}

It is generally known that mechanoelectrical transduction (MeT) channels detect mechanical signals and convert them into electrical signals [1]. MeT channels open very quickly and the channel latencies are typically less than $20 \mathrm{~ms}$ [31, 41, 52]. To date, members of four classes of membrane proteins that are related to mechanotransduction are considered to be pore-forming subunits of MeT channels: TRP, DEG/ENaC, Piezo, and TMC [31, 32, 34, 38, 53, 54]. Several members of the DEG/ ENaC family such as DEG-1, MEC-4/MEC-10, DEGT-1, and UNC-8, have been shown to form 

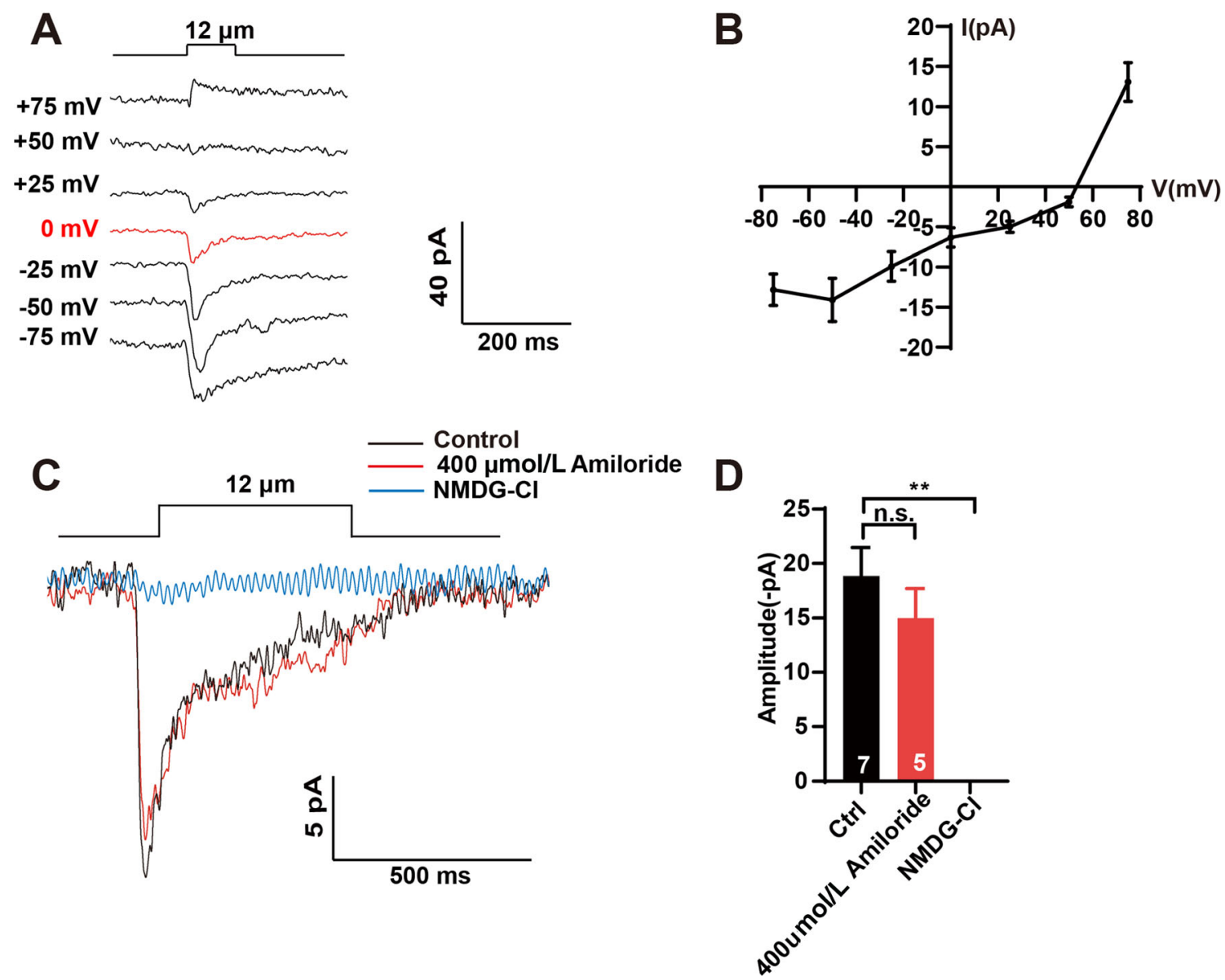

Fig. 4 A novel $\mathrm{Na}^{+}$channel mediates mechanotransduction in OLL neurons. A Sample traces of MRCs in an OLL neuron recorded with Cs-gluconate intracellular solution and $\mathrm{NaCl}$ extracellular solution. Cell membrane potentials are voltage-clamped at $+75 \mathrm{mV},+50 \mathrm{mV}$, $+25 \mathrm{mV}, 0 \mathrm{mV},-25 \mathrm{mV},-50 \mathrm{mV}$, and $-75 \mathrm{mV}$. B Current-voltage relationships (I-V curves) of MRCs in OLL neurons. Note that the reversal potential is $\sim 53 \mathrm{mV}$, which is similar to that of $\mathrm{Na}^{+}$selective channels. The $n$ values for the $+75 \mathrm{mV},+50 \mathrm{mV},+25 \mathrm{mV}$,
$0 \mathrm{mV},-25 \mathrm{mV},-50 \mathrm{mV}$, and $-75 \mathrm{mV}$ voltage-clamped groups were $3,8,8,8,9$, 9, and 9, respectively. C, D Sample traces (C) and quantification (D) of the MRCs in OLL neurons upon $400 \mu \mathrm{mol} / \mathrm{L}$ amiloride treatment and in $\mathrm{Na}^{+}$-free bath solution (NMDG-Cl). The $n$ values of the control group, the $400 \mu \mathrm{mol} / \mathrm{L}$ amiloride treatment group, and the NMDG-Cl solution group were 3, 7, and 5, respectively. Error bars indicate SEM; n.s., not significant, $P>0.05 ; * * P<0.01$.

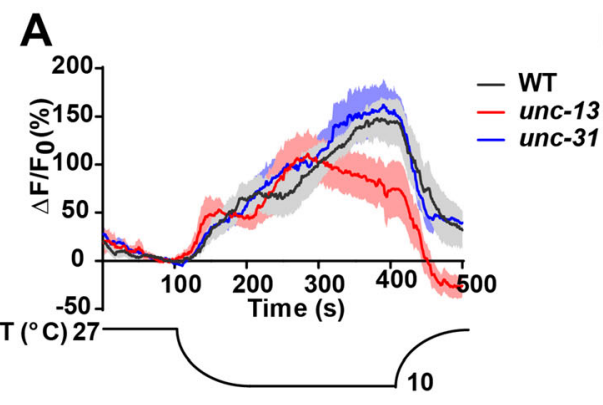

B
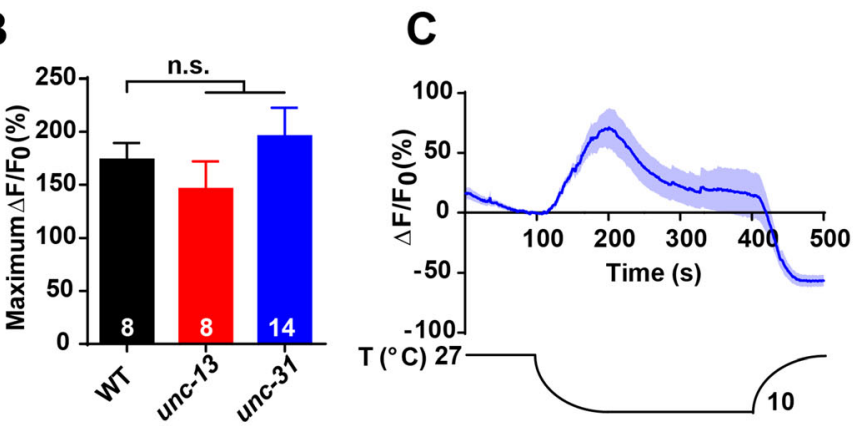

Fig. 5 OLL neurons cell-autonomously sense cold. A, B $\mathrm{Ca}^{2+}$ responses (A) and maximum $\Delta \mathrm{F} / \mathrm{F} 0$ changes (B) induced by cold stimulation in OLL neurons of wild type $(n=8)$, unc-13 mutants

mechanotransduction channels [21, 38, 40, 52]. However, the roles of putative MeT channels in sensory transduction are complicated and perplexing. TRP-4/TRPN forms the $(n=8)$, and $u n c-31$ mutants $(n=14)$. (C) Cold stimulation-evoked $\mathrm{Ca}^{2+}$ responses in isolated OLL neurons. $N=9$. Error bars indicate SEM; n.s., not significant.

MeT channel in the dopaminergic neurons [31, 55], whereas the OSM-9 TRP channel is dispensable for the mechanotransduction by ASH neurons, even though it is 
Fig. 6 OLL neurons sense cold in a TRPA-1-independent manner. $\mathbf{A}, \mathbf{B ~} \mathrm{Ca}^{2+}$ responses (A) and maximum $\Delta \mathrm{F} / \mathrm{F}_{0}$ changes (B) induced by cold stimulation in OLL neurons of wild type $(n=11)$, and trpa-1 mutants $(n=12)$. Error bars indicate SEM; n.s., not significant

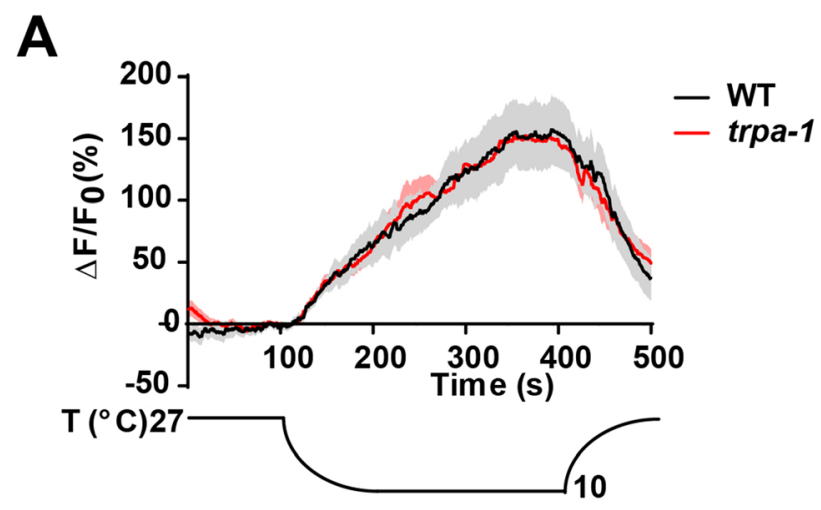

B

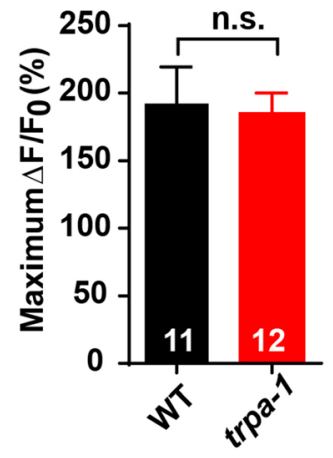

essential for ASH-mediated avoidance behaviors in response to nose touch, osmotic, and chemical stimuli $[52,56]$. In male ray neurons, OSM-9 modulates the kinetics of $\mathrm{Ca}^{2+}$ variations in response to mechanical stimulation [18]. These results support the idea that OSM-9 functions as a modulator but not as the primary MeT channel in mechanosensation.

In this study, we recorded robust, rapidly-adapting amiloride-insensitive MRCs in OLL neurons activated by mechanical force. The MeT channels in these neurons selectively permeated $\mathrm{Na}^{+}$ions, according to the reverse potential of MRCs which is similar to that for $\mathrm{Na}^{+}$channel conductance. TRP-4, TMC, and Piezo channels are all nonselective cation channels involved in mechanosensation, while DEG/ENaC are known to be amiloride-sensitive. As such, we ruled out TRP-4, TMC, Piezo, and ENaC channels as primary MeT channels in OLL neurons [1]. Therefore, the MeT channel of OLL neurons is an unreported mechanotransduction channel that is $\mathrm{Na}^{+}$-selective but not amiloride-insensitive. The molecular mechanisms by which OLL neurons function in mechanotransduction remain elusive. Thus, further studies are necessary to uncover this new mechanotransduction channel.

\section{An As-Yet-Unknown Cold-Sensing Receptor Exists in OLL Neurons}

The ability to sense ambient temperature is an indispensable trait for animal survival [1]. Cold temperatures, especially extremely low temperatures, threaten survival, causing severe damage to tissues and provoke cold pain sensation as warning signals [57]. A chain of temperaturesensing mechanisms have been reported to detect cold temperatures to alter behavior and physiology appropriately for survival [58]. Several cold receptors are present in cold-sensitive neurons or tissues [58]. The nematode $C$. elegans, which survives over a relatively wide temperature range from $12^{\circ} \mathrm{C}$ to $26^{\circ} \mathrm{C}$, provides a useful platform for studying the neuro-molecular basis of temperature sensation, particularly cold [59]. So far, only three cold receptors have been identified: TRPM8, TRPA1, and GLR3. TRPM8 participates in cooling sensation with an activation threshold at $\sim 26^{\circ} \mathrm{C}$. The TRPM8 cold receptor has been confirmed both in vivo and in vitro in mammals $[43,60,61]$. TRPA1 is ubiquitous and relatively conservative in its function [62]. In $C$.elegans, TRPA1 is responsible for cold sensation in PVD neurons and the intestine [22, 45]. However, OLL neurons exhibited robust $\mathrm{Ca}^{2+}$ transients evoked by cold stimuli with trpa-l mutation; thus TRPA1 did not contribute to the cold transduction in OLL neurons.

A recent study identified GLR-3 as a metabotropic cold receptor whose activation threshold is about $20^{\circ} \mathrm{C}$ [16]. GLR-3 is reported to be in ASER (the amphid neuron, single (AsE) ciliated ending, right side) to function in cold sensation and mediate cold-avoidance behavior. The $g l r-3$ gene is expressed in the ASER sensory neuron, RIA interneurons, and the intestine, as well as some other neurons, but not in OLL neurons (https://cengen.shinyapps. io/SCeNGEA/) [16]. Given that TRPM8 does not have evolutionarily conserved expression in C. elegans, it remains unclear which cold receptor exists in OLL neurons. Prospective studies are required to identify the cold receptor as well as the detailed transduction mechanisms.

In summary, we demonstrated that polymodal OLL neurons mediate both mechanotransduction and cold transduction cell-autonomously. We ruled out the DEG/ ENaC family proteins, TRP-4, TMC, and Piezo/Pezo-1 proteins in the mechanotransduction of OLL neurons, however, we provided fundamental insights into a novel mechano-sensitive $\mathrm{Na}^{+}$channel. Another interesting observation was that OLL neurons sensed low temperatures through an unknown cold receptor. Although three cold receptors have been identified, this unexpected cold receptor instigates new avenues for cold-sensing mechanisms. With further investigations, we expect that our study will contribute to advancing the molecular understanding of polymodal sensory neurons. 
Acknowledgements This work was supported by the National Natural Science Foundation of China (31471023, 31771113, and 31800878) and the China Postdoctoral Science Foundation (2020M671695, 2020T130592, 2019T120505, and 2018M640551). We thank the Caenorhabditis Genetic Center for the strains.

Conflict of interest All authors declare that they have no conflict of interest.

Open Access This article is licensed under a Creative Commons Attribution 4.0 International License, which permits use, sharing, adaptation, distribution and reproduction in any medium or format, as long as you give appropriate credit to the original author(s) and the source, provide a link to the Creative Commons licence, and indicate if changes were made. The images or other third party material in this article are included in the article's Creative Commons licence, unless indicated otherwise in a credit line to the material. If material is not included in the article's Creative Commons licence and your intended use is not permitted by statutory regulation or exceeds the permitted use, you will need to obtain permission directly from the copyright holder. To view a copy of this licence, visit http://creativecommons. org/licenses/by/4.0/

\section{References}

1. Goodman MB, Sengupta P. How Caenorhabditis elegans senses mechanical stress, temperature, and other physical stimuli. Genetics 2019, 212: 25-51

2. Hilliard MA, Apicella AJ, Kerr R, Suzuki H, Bazzicalupo P, Schafer WR. In vivo imaging of C. elegans ASH neurons: cellular response and adaptation to chemical repellents. Embo J 2005, 24: 63-72.

3. Wang H, Zylka MJ. Mrgprd-expressing polymodal nociceptive neurons innervate most known classes of substantia gelatinosa neurons. J Neurosci 2009, 29: 13202-13209

4. Ainsley JA, Pettus JM, Bosenko D, Gerstein CE, Zinkevich N, Anderson MG, et al. Enhanced locomotion caused by loss of the Drosophila DEG/ENaC protein Pickpocket1. Curr Biol 2003, 13: 1557-1563.

5. Grueber WB, Jan LY, Jan YN. Tiling of the Drosophila epidermis by multidendritic sensory neurons. Development 2002, 129: 2867-2878

6. Hwang RY, Zhong L, Xu Y, Johnson T, Zhang F, Deisseroth K, et al. Nociceptive neurons protect Drosophila larvae from parasitoid wasps. Curr Biol 2007, 17: 2105-2116.

7. Xiang Y, Yuan Q, Vogt N, Looger LL, Jan LY, Jan YN. Lightavoidance-mediating photoreceptors tile the Drosophila larval body wall. Nature 2010, 468: 921-926

8. White JG, Southgate E, Thomson JN, Brenner S. The structure of the nervous system of the nematode Caenorhabditis elegans. Philos Trans R Soc Lond B Biol Sci 1986, 314: 1-340

9. Li Z, Liu J, Zheng M, Xu XZ. Encoding of both analog- and digital-like behavioral outputs by one $\mathrm{C}$. elegans interneuron. Cell 2014, 159: 751-765.

10. Zou W, Cheng H, Li S, Yue X, Xue Y, Chen S, et al. Polymodal responses in $\mathrm{C}$. elegans phasmid neurons rely on multiple intracellular and intercellular signaling pathways. Sci Rep 2017, 7: 42295.

11. Chang HC, Paek J, Kim DH. Natural polymorphisms in C. elegans HECW-1 E3 ligase affect pathogen avoidance behaviour. Nature 2011, 480: 525-529.

12. Inglis PN, Ou G, Leroux MR, Scholey JM. The sensory cilia of Caenorhabditis elegans. WormBook 2007: 1-22.
13. Story GM, Peier AM, Reeve AJ, Eid SR, Mosbacher J, Hricik TR, et al. ANKTM1, a TRP-like channel expressed in nociceptive neurons, is activated by cold temperatures. Cell 2003, 112: 819-829.

14. Bandell M, Story GM, Hwang SW, Viswanath V, Eid SR, Petrus MJ, et al. Noxious cold ion channel TRPA1 is activated by pungent compounds and bradykinin. Neuron 2004, 41: 849-857.

15. Tsalik EL, Niacaris T, Wenick AS, Pau K, Avery L, Hobert O. LIM homeobox gene-dependent expression of biogenic amine receptors in restricted regions of the C. elegans nervous system. Developmental Biology 2003, 263: 81-102.

16. Gong J, Liu J, Ronan EA, He F, Cai W, Fatima M, et al. A coldsensing receptor encoded by a glutamate receptor gene. Cell 2019, 178: 1375-1386.e1311.

17. Anderson M, Zheng Q, Dong X. Investigation of pain mechanisms by calcium imaging approaches. Neurosci Bull 2018, 34: 194-199

18. Zhang H, Yue X, Cheng H, Zhang X, Cai Y, Zou W, et al. OSM9 and an amiloride-sensitive channel, but not PKD-2, are involved in mechanosensation in C. elegans male ray neurons. Sci Rep 2018, 8: 7192.

19. Zou W, Fu J, Zhang H, Du K, Huang W, Yu J, et al. Decoding the intensity of sensory input by two glutamate receptors in one C. elegans interneuron. Nat Commun 2018, 9: 4311.

20. Strange K, Christensen M, Morrison R. Primary culture of Caenorhabditis elegans developing embryo cells for electrophysiological, cell biological and molecular studies. Nat Protoc 2007, 2: 1003-1012

21. Tao L, Porto D, Li Z, Fechner S, Lee SA, Goodman MB, et al. Parallel processing of two mechanosensory modalities by a single neuron in C. elegans. Dev Cell 2019, 51: 617-631.e613.

22. Chatzigeorgiou M, Yoo S, Watson JD, Lee W-H, Spencer WC, Kindt KS, et al. Specific roles for DEG/ENaC and TRP channels in touch and thermosensation in C. elegans nociceptors. Nature Neuroscience 2010, 13: 861-868.

23. Chen TW, Wardill TJ, Sun Y, Pulver SR, Renninger SL, Baohan $\mathrm{A}$, et al. Ultrasensitive fluorescent proteins for imaging neuronal activity. Nature 2013, 499: 295-300.

24. Yoshida K, Hirotsu T, Tagawa T, Oda S, Wakabayashi T, Iino Y, et al. Odour concentration-dependent olfactory preference change in C. elegans. Nat Commun 2012, 3: 739.

25. Troemel ER, Kimmel BE, Bargmann CI. Reprogramming chemotaxis responses: sensory neurons define olfactory preferences in C. elegans. Cell 1997, 91: 161-169.

26. Bargmann CI, Hartwieg E, Horvitz HR. Odorant-selective genes and neurons mediate olfaction in C. elegans. Cell 1993, 74: $515-527$.

27. He KW, Shen LL, Zhou WW, Wang DY. Regulation of aging by unc-13 and sbt-1 in Caenorhabditis elegans is temperaturedependent. Neurosci Bull 2009, 25: 335-342

28. Richmond JE, Davis WS, Jorgensen EM. UNC-13 is required for synaptic vesicle fusion in C. elegans. Nat Neurosci 1999, 2: 959-964.

29. Zhou KM, Dong YM, Ge Q, Zhu D, Zhou W, Lin XG, et al. PKA activation bypasses the requirement for UNC-31 in the docking of dense core vesicles from C. elegans neurons. Neuron 2007, 56: 657-669.

30. Eastwood AL, Goodman MB. Insight into DEG/ENaC channel gating from genetics and structure. Physiology (Bethesda) 2012, 27: $282-290$

31. Kang L, Gao J, Schafer WR, Xie Z, Xu XZC. elegans TRP family protein TRP-4 is a pore-forming subunit of a native mechanotransduction channel. Neuron 2010, 67: 381-391

32. Jia Y, Zhao Y, Kusakizako T, Wang Y, Pan C, Zhang Y, et al. $\mathrm{TMC} 1$ and $\mathrm{TMC} 2$ proteins are pore-forming subunits of 
mechanosensitive ion channels. Neuron 2020, 105: 310-321.e313.

33. Moore C, Gupta R, Jordt SE, Chen Y, Liedtke WB. Regulation of pain and itch by TRP channels. Neurosci Bull 2018, 34: 120-142

34. Coste B, Xiao B, Santos JS, Syeda R, Grandl J, Spencer KS, et al. Piezo proteins are pore-forming subunits of mechanically activated channels. Nature 2012, 483: 176-181.

35. Yue X, Zhao J, Li X, Fan Y, Duan D, Zhang X, et al. TMC proteins modulate egg laying and membrane excitability through a background leak conductance in C. elegans. Neuron 2018, 97 : 571-585 e575.

36. Wang X, Li G, Liu J, Liu J, Xu XZ. TMC-1 mediates alkaline sensation in $\mathrm{C}$. elegans through nociceptive neurons. Neuron 2016, 91: 146-154.

37. Eastwood AL, Sanzeni A, Petzold BC, Park SJ, Vergassola M, Pruitt BL, et al. Tissue mechanics govern the rapidly adapting and symmetrical response to touch. Proc Natl Acad Sci U S A 2015, 112: E6955-6963.

38. O'Hagan R, Chalfie M, Goodman MB. The MEC-4 DEG/ENaC channel of Caenorhabditis elegans touch receptor neurons transduces mechanical signals. Nat Neurosci 2005, 8: 43-50

39. Hardie RC. Phototransduction in Drosophila melanogaster. J Exp Biol 2001, 204: 3403-3409

40. Arnadottir J, O'Hagan R, Chen Y, Goodman MB, Chalfie M. The $\mathrm{DEG} / \mathrm{ENaC}$ protein MEC-10 regulates the transduction channel complex in Caenorhabditis elegans touch receptor neurons. J Neurosci 2011, 31: 12695-12704

41. Christensen AP, Corey DP. TRP channels in mechanosensation: direct or indirect activation?. Nat Rev Neurosci 2007, 8: 510-521

42. Hodgkin AL, Huxley AF, Katz B. Measurement of currentvoltage relations in the membrane of the giant axon of Loligo. J Physiol 1952, 116: 424-448

43. Bautista DM, Siemens J, Glazer JM, Tsuruda PR, Basbaum AI, Stucky CL, et al. The menthol receptor TRPM8 is the principal detector of environmental cold. Nature 2007, 448: 204-208.

44. Hobert $O$. The neuronal genome of Caenorhabditis elegans. WormBook 2013: 1-106.

45. Xiao R, Zhang B, Dong Y, Gong J, Xu T, Liu J, et al. A genetic program promotes $\mathrm{C}$. elegans longevity at cold temperatures via a thermosensitive TRP channel. Cell 2013, 152: 806-817.

46. Chalfie M, Sulston J. Developmental genetics of the mechanosensory neurons of Caenorhabditis elegans. Dev Biol 1981, 82: 358-370

47. Chalfie M, Au M. Genetic control of differentiation of the Caenorhabditis elegans touch receptor neurons. Science 1989, 243: $1027-1033$
48. Mellem JE, Brockie PJ, Zheng Y, Madsen DM, Maricq AV. Decoding of polymodal sensory stimuli by postsynaptic glutamate receptors in C. elegans. Neuron 2002, 36: 933-944.

49. Budelli G, Ni L, Berciu C, van Giesen L, Knecht ZA, Chang EC, et al. Ionotropic receptors specify the morphogenesis of phasic sensors controlling rapid thermal preference in Drosophila. Neuron 2019, 101: 738-747.e733.

50. Bargmann CI, Thomas JH, Horvitz HR. Chemosensory cell function in the behavior and development of Caenorhabditis elegans. Cold Spring Harb Symp Quant Biol 1990, 55: 529-538

51. Hart AC, Kass J, Shapiro JE, Kaplan JM. Distinct signaling pathways mediate touch and osmosensory responses in a polymodal sensory neuron. J Neurosci 1999, 19: 1952-1958

52. Geffeney SL, Cueva JG, Glauser DA, Doll JC, Lee TH, Montoya $\mathrm{M}$, et al. $\mathrm{DEG} / \mathrm{ENaC}$ but not TRP channels are the major mechanoelectrical transduction channels in a $\mathrm{C}$. elegans nociceptor. Neuron 2011, 71: 845-857.

53. Pan B, Geleoc GS, Asai Y, Horwitz GC, Kurima K, Ishikawa K, et al. TMC1 and TMC2 are components of the mechanotransduction channel in hair cells of the mammalian inner ear. Neuron 2013, 79: 504-515.

54. Al-Sheikh U, Kang L. Molecular crux of hair cell mechanotransduction machinery. Neuron 2020, 107: 404-406

55. Li W, Kang L, Piggott BJ, Feng Z, Xu XZ. The neural circuits and sensory channels mediating harsh touch sensation in Caenorhabditis elegans. Nat Commun 2011, 2: 315

56. Colbert HA, Smith TL, Bargmann CI. OSM-9, a novel protein with structural similarity to channels, is required for olfaction, mechanosensation, and olfactory adaptation in Caenorhabditis elegans. J Neurosci 1997, 17: 8259-8269

57. Foulkes T, Wood JN. Mechanisms of cold pain. Channels (Austin) 2007, 1: 154-160

58. Schepers RJ, Ringkamp M. Thermoreceptors and thermosensitive afferents. Neurosci Biobehav Rev 2010, 34: 177-184

59. Schulenburg H, Felix MA. The natural biotic environment of Caenorhabditis elegans. Genetics 2017, 206: 55-86

60. McKemy DD, Neuhausser WM, Julius D. Identification of a cold receptor reveals a general role for TRP channels in thermosensation. Nature 2002, 416: 52-58

61. Peier AM, Moqrich A, Hergarden AC, Reeve AJ, Andersson DA, Story GM, et al. A TRP channel that senses cold stimuli and menthol. Cell 2002, 108: 705-715.

62. Nilius B, Appendino G, Owsianik G. The transient receptor potential channel TRPA1: from gene to pathophysiology. Pflugers Arch - Eur J Physiol 2012, 464: 425-458 